\title{
Treatment of recurrent glioblastoma with intra-arterial BCNU [1, 3-bis (2-chloroethyl)-1-nitrosourea]
}

\author{
Eberval Gadelha Figueiredo', Jose Weber Vieira de Faria², \\ Manoel Jacobsen Teixeira ${ }^{3}$
}

\begin{abstract}
Contemporary therapies for patients with glioblastomas remain marginally efficient, and recurrence following surgery, radiation therapy and adjuvant chemotherapy is practically universal. The major obstacles to the successful use of chemotherapy for CNS tumors are the drug delivery to the tumor site and the infusion of chemotherapeutic agents directly into the arterial supply of a tumor. The latter could provide a pharmacokinetic advantage by enhancing drug delivery to the tumor. Sixteen patients with recurrent unilateral glioblastomas treated with intra-arterial BCNU were evaluated retrospectively. During the infusion, eleven patients referred pain in the ipsilateral eye, five patients were nauseated, three reported headache, one patient presented mental confusion, while two presented focal signs. There were two deaths during the course of therapy. Four patients achieved temporary clinical improvement, seven showed disease stability, and three presented clinical deterioration. The median total survival time was 87.9 weeks. Unilateral vision loss and focal signs were observed as delayed complications of this treatment. This study has confirmed previous reports indicating that arterial chemotherapy is clearly not curative, and presents serious toxicity. Only through a randomized prospective study performed in a large series of patients can the questions concerning survival period increment be answered properly.
\end{abstract}

Key words: malignant gliomas, chemotherapy, carmustine, carotid artery, ophthalmic artery.

\section{Tratamento do glioblastoma recorrente com BCNU [1, 3-bis (2-chloroethyl)-1-nitrosourea]} intra arterial

\section{RESUMO}

Os tratamentos atuais para pacientes com glioblastoma permanecem pouco eficientes e a recorrência, acompanhando cirurgia, radioterapia e quimioterapia, é a regra geral. O maior obstáculo para o sucesso da quimioterapia para os tumores do SNC é a disponibilização da droga no sitio do tumor sendo que a infusão do agente quimioterápico diretamente na trama arterial da lesão pode proporcionar vantagens por maior liberação da substância diretamente no tumor. Estudamos retrospectivamente dezesseis pacientes com glioblastomas recorrentes, unilaterais, que foram tratados com BCNU intra-arterial; durante a infusão, onze pacientes sentiram dor no olho ipsilateral, cinco ficaram nauseados, três queixaram-se de cefaléia, um apresentou confusão mental e dois apresentaram sinais focais. Ocorreram duas mortes durante a terapia. Quatro pacientes apresentaram melhora clinica temporária, sete apresentaram estabilização e três apresentaram deterioração. A média de sobrevida total foi de 87,9 semanas. Perda da visão unilateral e sinais focais

\section{Correspondence}

Eberval Gadelha Figueiredo Rua Oscar Freire 1399 / Apto 171 05409-010 São Paulo SP - Brazil E-mail: ebgadelha@yahoo.com

Received 27 August 2009

Received in final form 17 April 2010 Accepted 27 April 2010 foram complicações tardias. Este estudo confirmou trabalhos anteriores indicando que

Division of Neurosurgery, University of São Paulo, School of Medicine, São Paulo SP, Brazil: 'Supervisor, Division of Neurological Surgery, University of São Paulo Medical School, São Paulo SP, Brazil; ${ }^{2}$ Fellow Physician, Division of Functional Neurological Surgery, University of São Paulo Medical School, São Paulo SP, Brazil. Chief of Division of Neurological Surgery, Federal University of Uberlândia Medical School, Uberlândia MG, Brazil; ${ }^{3}$ Chairman, Division of Neurological Surgery University of São Paulo Medical School, São Paulo SP, Brazil. 
a quimioterapia intra-arterial claramente não é curativa, séria toxicidade pode ocorrer e somente um estudo prospectivo e randomizado, realizado em uma serie maior de pacientes, poderá responder questões sobre o aumento do tempo de sobrevida de forma adequada. Palavras-chave: gliomas malignos, quimioterapia, carmustina, artéria carótida, artéria oftálmica.

Contemporary therapies for patients with malignant gliomas remain only marginally efficient, and the recurrence rate following surgery, radiation therapy and adjuvant chemotherapy is practically universal. There are several challenges related to the treatment of central nervous system (CNS) tumors with chemotherapy. Among these challenges, the heterogeneity of malignant primary brain tumors, presenting with a variety of histological subtypes and similar tumors may be responsible for the different tumor behavior regarding treatment. Additionally, the number of chemotherapeutic agents available to treat a variety of CNS tumors is limited ${ }^{1}$, while drug resistance involving P-glycoprotein ${ }^{2}$ and the ability of tumor cells to repair DNA damage induced by cytotoxic agent or the use of alternative pathways of metabolism ${ }^{3}$ also have to be considered.

Failure to eradicate local tumor growth is a major factor contributing to poor outcome, as indicated by the development of $90 \%$ of glioblastoma (GBM) recurrences at, or adjacent to, the original tumor ${ }^{4}$. A major obstacle for the successful use of chemotherapy for CNS tumors drug delivery to the tumor site. CNS tumor response to chemotherapy is limited by inadequate intracellular concentrations of the drug, inadequate drug exposure time and characteristics of drug delivery across the blood brain barrier (BBB). There is a challenge on the ability for drug delivery across the $\mathrm{BBB}$, a physical and physiologic barrier that regulates the entry of molecules to the brain. The $\mathrm{BBB}$ is highly effective for protecting the CNS from various toxins, but it is also effective at excluding therapeutic agents such as chemotherapies and antibiotics ${ }^{5}$. Iatrogenic disruption of the BBB prior to administering systemic chemotherapy has had greater success ${ }^{6}$.

Nitrosoureas, which include BCNU (1,3-bis(2chloroethyl)-1-nitrosourea), are the primary single-agent therapy used for the treatment of gliomas ${ }^{7}$. Nitrosoureas are small, lipid-soluble, non-ionized alkylating agents ${ }^{8}$, which have been administered into the arteries (IA), with some success ${ }^{9}$. However, the positive responses have been modest, and the technique is associated with significant toxicity. Furthermore, its true activity for patients with recurrent or progressive malignant gliomas remains uncertain. The literature reports single-agent response rates of $40 \%$ to $50 \%$, but this is seldom seen in the clinical practice. The real objective response rate of nitrosoureas remains unknown, although many authors believe it to be less than $10 \%$ for glioblastoma ${ }^{9}$. So far, IA administration alone has not really shown improvement in the outcome for patients with brain cancer ${ }^{10,11}$, and no study has yet demonstrated a significant benefit of intra-arterial chemotherapy over its intravenous counterpart ${ }^{12}$.. No large randomized trial has yet demonstrated that intracarotid administration of chemotherapy is more advantageous than its systemic administration ${ }^{13}$. The objective of this paper is to evaluate and describe the treatment of recurrent glioblastoma with intra-arterial $\mathrm{BCNU}$.

\section{METHOD}

Sixteen patients with postoperative recurrent, unilateral, supratentorial glioblastomas in the medial cerebral artery territory were referred for intra-arterial carotid infusion chemotherapy using Seldinger technique. All patients had been submitted to surgery ( 3 biopsy and 13 craniotomy), and had previously received whole brain radiotherapy (RT) consisting of a median dose of 6,000 rads (one patient received 5,000 rads) No patient had previously received chemotherapy. The corticosteroid dexamethasone was administered when clinically indicated, with the dose adjusted at weekly intervals; and diphenylhydantoin and phenobarbital were used as anticonvulsant agents. Written informed consent was obtained from all patients.

Patients were eligible for this treatment if the following criteria were met: [1] the tumor was histologically confirmed as glioblastoma; [2] the tumor was recurrent; [3] radiotherapy had been administered; [4] white blood cell count was $>4,000 / \mathrm{mm}^{3}$ and platelet count was $>125,000 /$ $\mathrm{mm}^{3}$; [5] liver and renal functions were $<2$ times higher than normal values; [6] Karnofsky performance status at time of study entry was $\geq 70 \%$. Active infections and pregnancy were considered as exclusion criteria for patient selection. A neurological examination with Karnofsky functional performance rating, complete blood count, and platelet count were performed during treatment. $\mathrm{Pa}-$ tients were premedicated with Inoval ${ }^{\circ}$ (Droperidol and Fentalina) $2 \mathrm{ml}$ IV during the drug infusion, as required.

BCNU was administered through a selective internal carotid artery catheter placed percutaneously, using the femoral approach and immediately prior to infusion. BCNU was dissolved in $1.0 \mathrm{ml}$ of absolute ethanol/100 $\mathrm{mg} \mathrm{BCNU}$, and given at $250 \mathrm{mg}$ per square meter of body surface area. It was then made up to a volume of $150 \mathrm{cc}$ 
with normal saline, and this solution was infused using an infusion pump, at 400 to $600 \mathrm{cc} / \mathrm{hr}$. In all patients, these treatments were repeated every 6 weeks. Follow-up was carried-out on an outpatient basis, for 117 weeks in average. Complications related to the procedure were listed and neurological final outcome was retrieved from hospital records. Data are summarized in the Table.

\section{RESULTS}

Sixteen patients with recurrent unilateral glioblastomas were treated with pulse dose of IA BCNU via transfemoral internal carotid catheterization. There were no complications related to the use of the catheter and the desired placement was achieved in all cases. During the infusion, eleven patients felt moderately severe pain in the ipsilateral eye, and five patients were nauseated for 3 to 5 hours following the infusion. Three patients reported headache, one patient presented mental confusion, while two patients presented focal signs and three patients had amaurosis. There were two deaths related to the tumor during the course of therapy. Karnofsky rating improved in four patients, worsened in three patients, and remained unaltered in seven patients (stable disease). After three to seven cycles of chemotherapy, six patients showed a decrease in tumor size and in the surrounding edema, as assessed by contrast enhanced CT scanning, in cases with partial response. Ten patients presented no changes and, in this group, three had not undergone CT scan. Four patients achieved a temporary period of clinical improvement, seven patients had stable disease and three patients presented neurological deterioration. The median survival time from the onset of chemotherapy in the group of 16 patients was over 66.6 weeks. The median survival time from the operation act was over 21.3 weeks. The median total survival time was over 87.9 weeks. Unilateral loss of vision was a delayed complication in three patients, while two patients developed focal signs and recognized leukoencephalopathy or tumor necrosis. Patients' characteristics are listed in the Table.

\section{DISCUSSION}

Chemotherapy is currently being used as an adjunctive treatment for malignant primary tumors, progressive benign tumors, and recurrent or resistant tumors. The treatment of glioblastoma at recurrence remains palliative with only small numbers of long-term responses. In the present series, cases of combined prior radiotherapy, surgery and consecutive intra-arterial BCNU were assessed for patients with unilateral supratentorial glioblastoma. A modest improvement in the median survival with the addition of single-agent or combination chemotherapy to radiotherapy has been demonstrated in several trials ${ }^{14}$. An additional study that reviewed data from two
Table. Patient characteristics.

\begin{tabular}{|c|c|}
\hline Characteristics & Intra-arterial $(n=16)$ \\
\hline $\operatorname{Sex}(M / F)$ & $10 / 6$ \\
\hline \multicolumn{2}{|l|}{ Age } \\
\hline Median & 55 \\
\hline Range & $48-67$ \\
\hline \multicolumn{2}{|l|}{ KPS } \\
\hline Median & 80 \\
\hline Range & $70-100$ \\
\hline \multicolumn{2}{|l|}{ Tumor location } \\
\hline Frontal & 4 \\
\hline Frontotemporal & 3 \\
\hline Frontoparietal & 3 \\
\hline Parietal & 3 \\
\hline Temporoparietal & 2 \\
\hline Parieto-occipital & 1 \\
\hline \multicolumn{2}{|l|}{ Pretreatment } \\
\hline Biopsy & 3 \\
\hline Craniotomy & 13 \\
\hline Repeat surgery & 1 \\
\hline \multicolumn{2}{|l|}{ Radiotherapy } \\
\hline $6,000 \mathrm{rd}$ & 15 \\
\hline $5,000 \mathrm{rd}$ & 1 \\
\hline \multicolumn{2}{|l|}{ Number of cycles } \\
\hline Median & 10 \\
\hline Range & $6-12$ \\
\hline Survival after surgery & 21.3 weeks \\
\hline Survival after chemotherapy & 66.6 weeks \\
\hline Total survival (M) & 97.9 weeks \\
\hline
\end{tabular}

KPS: Karnofsky performance score.

Brain Tumor Study Group protocols (including patients with glioblastoma multiforme and other types of anaplastic gliomas) demonstrated an increased number of longterm survivors in the group of patients who received adjuvant chemotherapy with BCNU compared with radiation alone, regardless of prognostic factors ${ }^{15,16}$. A metaanalysis of 16 randomized clinical trials, which included more than 3000 patients treated between 1975 and 1989, demonstrate a survival benefit for those patients with malignant glioma treated with radiation and adjuvant chemotherapy compared with those treated with radiation therapy alone ${ }^{17}$. Some studies indicate a modest benefit of the single agent $\mathrm{BCNU}$ when added to $\mathrm{RT}^{17,18}$.

Malignant astrocytomas can be treated with IA BCNU followed by radiation therapy with a therapeutic efficacy that appears to be equal to or better than that of radiation therapy followed by IV $\mathrm{BCNU}^{19}$. Infusion of chemotherapeutic agents directly into the arterial supply of a tumor 
can provide a pharmacokinetic advantage by enhancing drug delivery to the tumor without increasing systemic drug exposure ${ }^{20,21}$. Intra-arterial (IA) administration of a drug is designed to increase the drug-concentration delivered to a vascular territory by eliminating the first passage metabolism. However, for drugs that have rapid transit trough the CNS, there may be limited dwell time, resulting in limited efficacy. In a study involving 12 adults patients with recurrent glioblastoma, intra-arterial BCNU infusion resulted in a median survival time of 54 weeks following recurrence ( 92 weeks after diagnosis). However, no major improvement in survival time was demonstrated in a group of 43 patients treated adjuvantly after receiving irradiation. It was hypothesized that the group receiving adjuvant intra-arterial $\mathrm{BCNU}$ had radiation-related changes that limited drug penetration into tissue, although the effects of radiation on drug delivery across the $\mathrm{BBB}$ have been controversial ${ }^{22}$. A study by Levin and colleagues using radiolabeled $\mathrm{BCNU}$ demonstrated a fourfold increase in BCNU concentration in the brain following intracarotid administration compared with intravenous administration ${ }^{23}$. A study using continuous-infusion of cisplatin plus BCNU before RT demonstrated no improvement in survival compared with $\mathrm{RT}$ and $\mathrm{BCNU}$ alone ${ }^{24}$. On the other hand, the simultaneous administration of cisplatin and $\mathrm{BCNU}$, together with RT, resulted in more toxicity and provided no significant improvement in survival ${ }^{25}$. The comparison of intra-arterial ACNU and carboplatin versus intravenous cisplatin and $\mathrm{BCNU}$ in newly diagnosed patients with glioblastoma provided no conclusive evidence of benefit for either method ${ }^{26}$. The mean survival duration in the present study was 87.9 weeks after diagnosis; 21.3 weeks after surgery; and 66.6 weeks after chemotherapy.

In a study combining intra-arterial (IA) and systemic chemotherapy in patients with grade II to IV gliomas, response rates up to $54 \%$ were demonstrated, but $31 \%$ of patients developed neurotoxicity, while 12\% developed serious permanent local toxicity ${ }^{27}$. In the present study, a delayed complication of unilateral loss of vision was observed in three patients, while focal signs and recognized leukoencephalopathy or tumor necrosis were observed in two cases. Tissue regions that receive high concentrations of the drug are at risk for toxicity, whereas low drug concentrations in other tissue regions may be subtherapeutic $^{28}$. In addition to increasing drug levels in the tumor, IA technique increases drug levels in the area of normal brain that is supplied by that artery, leading to greater neurotoxicity. For example, intracarotid administration of BCNU has been associated with ocular toxicity, stroke, and an encephalitic profile ${ }^{29}$. The ocular complications of intracarotid infusion of drugs for brain-tumor chemotherapy may be reduced by infusion of the chemo- therapeutic agent into the carotid artery above the origin of the ophthalmic artery ${ }^{30}$. One difficulty with the intraarterial administration is that there may be no uniform drug distribution within the brain or the tumor after the intracarotideal infusion, due to poor mixing or streaming of the drug solution within the artery ${ }^{31}$. Similarly, in patients undergoing resection for recurrent GBM, placement of carmustine wafers only provided a modest extension of survival ${ }^{32}$. Implanted therapies with polymerbased drug delivery, placed in the surgical cavity at the time of the tumor debulking, resulted in improved survival of roughly 2 months ${ }^{32,33}$. The ocular complications of intracarotid infusion of drugs for brain-tumor chemotherapy may be minimized by infusion of the chemotherapeutic agent into the carotid artery above the origin of the ophthalmic artery ${ }^{30}$. Additionally, the frequency of visual loss could be decreased if the concentration of the ethanol diluent was lowered ${ }^{19}$.

There are controversial data questioning the increase in survival time with associated radiotherapy and chemotherapy, the optimal dosage of chemotherapy, the role of intra-arterial treatment, the real toxicity of drugs association and the best place to infuse the drugs. The treatment of glioblastoma multiforme remains a difficult problem for neurosurgeons. The present study has corroborated the observation that intra-arterial chemotherapy is clearly not curative, with serious toxicity. Therefore, only randomized prospective studies performed on a large series of patients may answer these problems properly.

\section{REFERENCES}

1. Kraemer DF, Fortin D, Neuwelt EA. Chemotherapeutic dose intensification for treatment of malignant brain tumors: rrecent developments and future directions. Cur Neurol Neurosc Rep 2002;2:216-224

2. Tatsuta T, Naito M, Oh-hara T, et al. Functional involvement of P-Glycoprotein in blood-brain barrier. J Biol Chem 1992;267:20383-20391.

3. Levin V. Pharmacological principles of brain tumor chemotherapy. In: Thompson R, Green J (Eds). Advances in neurology. New York: Raven Press 1976:315-325.

4. Wallner KE, Galicich JH, Krol G, Arbit E, Malkin MG. Pattern of failure following treatment for glioblastoma multiforme and anaplastic astrocytoma. Int J Radiat Oncol Biol Phys 1989;16:1405-1409.

5. Deeken JF, Loscher W. The blood brain barrier and cancer: transports, treatment, and Trojan horses. Clin Cancer Res 2007;13:1663-1674.

6. Fortin D, Desjardins A, Benko A, et al. Enhanced chemotherapy delivery by intraarterial infusion and blood brain barrier disruption in malignant brain tumors: The Sherbrooke experience. Cancer 2005;103:2606-2615.

7. Moynihan T, Grossman S. The role of chemotherapy in the treatment of primary tumors of the central nervous system. Cancer Invest 1994;12:88-97.

8. Wheeler G, Bowdon B, Grimsley J, et al. Interrelationships of some chemical, physiochemical, and biological activities of several 1-(2-haloethyl)-1-nitrosoureas. Cancer Res 1974;34:194-200.

9. Newton H, Grahovac Z, Hugenholtz H, et al. Combined intraarterial and systemic chemotherapy for intracerebral tumors. Neurosurgery 1987;21: 207-214.

10. Dropcho EJ, Rosenfeld SS, Vitek J, et al. Phase II study of intracarotid or selective intracerebral infusion of cisplastin for treatment of recurrent anaplastic gliomas. J Neurooncol 1998;36:191-198.

11. Ashby LS, Shapiro WR. Intrarterial cisplatin plus oral ectoposide for the treatment of recurrent malignant gliomas: a phase II study. J Neurooncol 2001;51:67-86 
12. Madajewicz S, Chowhan N, Tfayli A, et al. Therapy for patients with high grade astrocytoma using intraarterial chemotherapy and radiation therapy. Cancer 2000;88:2350-2356.

13. Shapiro W, Gree $S$, Burger $P$, et al. A randomized comparison of intra-arterial versus intravenous BCNU, with or without intravenous 5-fluoruracil, for newly diagnosed patients with malignant gliomas. J Neurosurg 1992; 76:772-781.

14. Green S, Byar D, Walker M, et al. Comparisons of carmustine, procarbazine, and high-dose methylprednisolone as additions to surgery and radiotherapy for the treatment of malignant gliomas, Cancer Treat Rep 1983;67: 121-132.

15. DeAngelis L, Burger $P$, Green $S$, et al. Malignant glioma: who benefits from adjuvant chemotherapy? Ann Neurol 1998;44:691-695.

16. Shapiro W. Therapy of adulto malignant brain tumrors: what have the clinical trials taught us? Semin Oncol 1986;13:38-45.

17. Fine H, Dear K, Loeffler J, et al. Meta-analysis of radiation therapy with and without adjuvant chemotherapy for malignant gliomas in adults. Cancer 1993;71:2585-2597.

18. Stewart LA. Chemotherapy in adult high-grade gliomas: a systematic review and meta-analysis of individual patient data from 12 randomised trials. Lancet 2002;359:1011-1018.

19. Greenberg HS, Ensminger WD, Chandler WF, et al. Intra-arterial BCNU chemotherapy for treatment of malignant gliomas of the central nervous system. J Neurosurg 1984;61:423-429.

20. Collins J. Pharmacologic rationale for regional drug delivery. J Clin Oncol 1984;2:498-504.

21. Lutz R, Dedrik R, Boretos J, et al. Mixing studies during intracarotid arterial infusions in an in vitro model. J Neurosurg 1986;64:277-283.

22. Hochberg F, Pruitt A, Beck D, et al. The rationally and methodology for intra-arterial chemotherapy whith BCNU as treatment for glioblastoma multiform. J Neurosurg 1985;63:876-880.

23. Silvane A, Eoli M, Salmaggi A, et al. Intra-arterial ACNU and carboplatin versus intravenous chemotherapy with cisplatin and BCNU in newly diagnosed patients with glioblastoma. J Neurol Sci 2002;23:219-224.
24. Grossman SA, O Neill A, Grunnet M, et al. Phase III study comparing three cycles of infusional carmustine and cisplatin followed by radiation therapy and concurrent carmustine in patients with radiation therapy and concurrent carmustine in patients with newly diagnosed supratentorial glioblastoma multiforme: Estern Cooperative Oncology Grooup Trial 2394. J Clin Oncol 2003;21:1485-1491.

25. Buckner JC, Ballman KV, Michalak JC, et al. Phase III trial of carmustine and cisplatin compared with carmustine alone and standard radiation therapy or accelerated radiation therapy in patients with glioblastoma multiforme: North Central Cancer Treatment Group 93-72-52 and Southwest Oncology Group 9503 Trials. J Clin Oncol 2006;24:3871-3879.

26. Levin V, Kabra P, Freeman-Dove M. Pharmacokinetics of intracarotid artery 14-C BCNU in the squired Monkey. J Neurosurg 1978:48:587-593.

27. Stewart D, Grahovac Z, Hugenholtz H, et al. Combined intra-arterial and systemic chemotherapy for intracerebral tumors. Neurosurgery 1987;21: 207-214.

28. Saris S, Wright D, Oldfield E, et al. Intravascular streaming and variable delivery to brain following carotid artery infusions in the Sprague-Dawley rat J Cereb Blood Flow 1988:8:116-120.

29. Rosenblum M, Delattre J, Shapiro W. Fatal necrotizing encephalopathy complicating treatment of malignant gliomas with intra-arterial BCNU and irradiation: a pathological study. J Neurooncol 1989;7:269-281.

30. Kapp JP, Ross RL, Tucker EM. Supraophthalmic carotid infusion for brain-tumor chemotherapy. Technical note. J Neurosurg 1983;58:616-618.

31. Saris $\mathrm{S}$, Blasberg R, Carson R, et al. Intravascular streaming during carotid artery infusions. J Neurosurg 1991;74:763-772

32. Brem H, Piantadosi S, Burger PC, et al. Placebo-controlled trial of safety and efficacy of intraoperative controlled delivery by biodegradable polymers of chemotherapy for recurrent malignant gliomas. The Polymer-Brain Tumor Treatment Group. Lancet 1995;345:1008-1012.

33. Westphal M, Hilt DC, Bortey E, et al. A phase 3 trial of local chemotherapy with biodegradable carmustine (BCNU) wafers (Gliadel wafers) in patients with primary malignant gliomas. Neuro Oncol 2003;5:79-88. 